The European Journal of Public Health, Vol. 26, No. 3, 422-430

(C) The Author 2016. Published by Oxford University Press on behalf of the European Public Health Association.

This is an Open Access article distributed under the terms of the Creative Commons Attribution Non-Commercial License

(http://creativecommons.org/licenses/by-nc/4.0/), which permits non-commercial re-use, distribution, and reproduction in any medium,

provided the original work is properly cited. For commercial re-use, please contact journals.permissions@oup.com

doi:10.1093/eurpub/ckv231 Advance Access published on 10 January 2016

\title{
Linking databases on perinatal health: a review of the literature and current practices in Europe
}

\author{
M. Delnord ${ }^{1}$, K. Szamotulska ${ }^{2}$, A.D. Hindori-Mohangoo ${ }^{3,4}$, B. Blondel ${ }^{1}$, A.J. Macfarlane ${ }^{5}$, \\ N. Dattani ${ }^{5}$, C. Barona ${ }^{6}$, S. Berrut ${ }^{7}$, I. Zile ${ }^{8}$, R. Wood $^{9}$, L. Sakkeus ${ }^{10}$, M. Gissler ${ }^{11}$, J. Zeitlin ${ }^{1}$, \\ and the Euro-Peristat Scientific Committee*
}

\begin{abstract}
1 INSERM, UMR 1153 Obstetrical, Perinatal and Pediatric Epidemiology Research Team (Epopé), Center for Epidemiology and Statistics Sorbonne Paris Cité, DHU Risks in pregnancy, Paris-Descartes University, Paris, France

2 Department of Epidemiology and Biostatistics, National Research Institute of Mother and Child, Warsaw, Poland

3 Netherlands Organization for Applied Scientific Research, TNO Healthy Living, Department Child Health, Leiden, The Netherlands

4 Anton de Kom University of Suriname, Faculty of Medical Sciences, Department Public Health, Paramaribo, Suriname 5 Centre for Maternal and Child Health Research, City University London, London, UK

6 General Directorate of Public Health, Generalitat Valenciana, Valencia, Spain

7 Swiss Federal Statistical Office, Section Health, Neuchâtel, Switzerland

8 Centre for Disease Prevention and Control of Latvia, Riga, Latvia

9 Information Services Division, NHS National Services Scotland, Edinburgh, Scotland, UK

10 Estonian Institute for Population Studies, Tallinn University, Tallinn, Estonia

11 Information Services Department, THL National Institute for Health and Welfare, Helsinki, Finland
\end{abstract}

*The members of the Euro-Peristat Scientific Committee are listed in the Acknowledgements.

Correspondence: Marie Delnord, INSERM UMR 1153, Obstetrical, Perinatal and Pediatric Epidemiology Research Team (Epopé), Research Center for Epidemiology and Biostatistics Sorbonne Paris Cité (CRESS), Maternité de Port Royal, 53 Avenue de I'Observatoire, 75014 Paris, France, Tel: +33 1423455 86, Fax: +01 432689 79, e-mail: Marie.delnord@inserm.fr

Background: International comparisons of perinatal health indicators are complicated by the heterogeneity of data sources on pregnancy, maternal and neonatal outcomes. Record linkage can extend the range of data items available and thus can improve the validity and quality of routine data. We sought to assess the extent to which data are linked routinely for perinatal health research and reporting. Methods: We conducted a systematic review of the literature by searching PubMed for perinatal health studies from 2001 to 2011 based on linkage of routine data (data collected continuously at various time intervals). We also surveyed European health monitoring professionals about use of linkage for national perinatal health surveillance. Results: 516 studies fit our inclusion criteria. Denmark, Finland, Norway and Sweden, the US and the UK contributed $76 \%$ of the publications; a further 29 countries contributed at least one publication. Most studies linked vital statistics, hospital records, medical birth registries and cohort data. Other sources were specific registers for: cancer (70), congenital anomalies (56), ART (19), census (19), health professionals (37), insurance (22) prescription (31), and level of education (18). Eighteen of 29 countries $(62 \%)$ reported linking data for routine perinatal health monitoring. Conclusion: Research using linkage is concentrated in a few countries and is not widely practiced in Europe. Broader adoption of data linkage could yield substantial gains for perinatal health research and surveillance.

\section{Introduction}

International comparisons of perinatal health indicators provide valuable evidence for public policy planning and practice by allowing benchmarking across countries, and revealing the diversity in clinical practice related to antenatal and delivery care. $^{1,2}$ In Europe, recent results from the European Perinatal Health Report 2010 (EPHR 2010) showed wide differences in health outcomes and indicators of clinical practice. For example in 2010 , stillbirth rates ranged from 2.0 to 4.0 per 1000 births and cesarean section rates ranged from $13 \%$ to $47 \%$ of total births. ${ }^{1,3-5}$

International comparisons are limited by the quality and completeness of information held in national data systems however. The EPHR 2010, which reported on population-based aggregate data from 26 EU Member States, plus Iceland, Norway and Switzerland ${ }^{6}$ showed gaps in data availability of many key indicators. For instance, only 19 out of 29 countries had data on the gestational age distribution of neonatal deaths, 17 on smoking during pregnancy and 5 on severe maternal morbidity. ${ }^{7}$ To compile the Euro-Peristat indicators, countries used multiple data sources: birth certificates, death certificates, medical birth registers, specific registers or audits, hospital discharge data, professional databases and surveys. These varied in their inclusion criteria and data quality, raising questions about comparability. ${ }^{1,6}$

Record linkage between health, civil and administrative data systems is one way to increase the completeness, quality and breadth of data available for perinatal health monitoring and research. Linkage is the term used to describe the process of merging individual records from two or more datasets in order to extend the range of data items available. ${ }^{6}$ Linked data have been used to generate knowledge and investigate the association between 
population risk factors and a wide array of both maternal ${ }^{7,8}$ and infant health outcomes. ${ }^{9-11}$ However, there is currently no information on the extent to which linkage is used in Europe for surveillance and research. In this study, our objectives were to assess: the types of linkage done for perinatal health research and monitoring, the maternal and infant health themes and outcomes explored in research using linkage, and potential gaps in current record linkage practices in European countries.

\section{Methods}

This study was based on data from a systematic review of publications on linkage, and on information collected within the EuroPeristat project about the use of linkage in routine perinatal health monitoring.

\section{Review of publications based on linked data from routine sources}

\section{Search strategy}

We searched PubMed for perinatal health studies based on linkage of routine data sources published between 2001 and 2011. Routine data sources are those that collect information continuously or regularly (in the case of surveys). We used the following key works: data linkage, perinat ${ }^{*}$ matern*, link* ${ }^{*}$, registr*, medical record linkage, infant newborn and birth certificates. Publications were screened by the first author based on information provided in the titles and abstracts. We identified 990 studies from which we excluded conference reports, summaries and reviews. We did not include studies with data that are not regularly repeated. We included research related to the perinatal period: pregnancy, delivery and the post-partum, which linked two or more routine datasets together or paired mother and newborn records within the same data collection system. Studies linking pregnancy or birth cohorts to routine datasets were included. To increase coverage, we contacted Scientific Committee (SC) members of the Euro-Peristat network for any additional research articles that we might have missed from their countries. Our final sample included 516 studies. More information on search terms and the database are available from the authors on request.

\section{Data extraction}

From each study, we extracted the types and number of routine data sources used, the main outcome variables, the dependent variables, country of origin and year of publication. Principal types of sources were: civil registration (birth and death certificates), hospital discharge data (i.e. admissions, inpatient and other medical records) and medical birth registers (which hold birth data augmented with clinical information about each delivery and birth). ${ }^{1}$

We described how linkage was used in perinatal health research by classifying publications according to themes and linkage types within countries and by year. We categorized studies based on their outcome variables into the following research themes: (i) fetal, neonatal and child health, (ii) maternal health and (iii) methods this theme included studies focused on validating data through record linkage use, or on usage of specific data linkage techniques such as probabilistic vs. deterministic methods. We further assessed which of our included studies were longitudinal. We flagged studies as 'longitudinal' when researchers studied the impact of health events outside the perinatal period (i.e. exposure to environmental risk factors during pre-conception) on outcomes during the perinatal period (i.e. birth weight), or when researchers studied the influence of perinatal risk factors (i.e. preterm birth) on longer term maternal or child health outcomes (i.e. educational attainment). Data extraction was carried out by the first author and validated by the co-authors.

\section{Analysis}

We identified recurrent and less common linkages based on the types of data sources used, such as linkage of vital statistics data and medical birth register data, and how often these were linked across studies. All original data sources were accounted for in the analyses. In the Netherlands for instance, birth data held in the medical birth register are compiled from data held in the obstetric, paediatric and neonatal registers. Similarly, linked datasets such as the Oxford Record Linkage Study were described in terms of their constituent datasets (i.e. linkage of civil registration data, hospital discharge data and domiciliary midwives case notes). Data were analyzed using STATA 13.0 software (StataCorp LP, College Station, TX). We used the software to describe the overall characteristics of the studies included in this review such as the time period, country, or the topic area, and also to identify and keep track of the different possible types of linkages available in the literature and their associated study outcomes.

\section{Data on routine linkages from the Euro-peristat network}

We used data collected for the EPHR 2010 supplemented by additional information from the Euro-Peristat Scientific Committee (SC). Euro-Peristat indicators were compiled from routine aggregate data available from population-based registers. As part of the data collection exercise, SC members were asked to describe the characteristics of their national data systems and in particular: inclusion criteria, year in which the data source began, estimates of coverage (i.e. nationals vs. residents), capacity and use of linkage, and plans to modify or extend the data source.

SC members were also asked to confirm the availability in routine of the most prevalent linkage types identified in our review of the literature: (i) linkage of birth and death certificates, (ii) vital statistics and medical birth register data, (iii) medical birth register data and hospital discharge data and (iv) vital statistics and hospital discharge data. In our study, vital statistics data included: birth certificates, death certificates and/or data on causes of death. We identified hospital discharge data, as all data extracted from admissions, inpatient care or other clinical records (i.e. maternity records or pediatric records). SC members could specify any other routine linkage available in their country which might not have been recorded for the Euro-Peristat data collection.

\section{Results}

Table 1 shows that there were wide variations in the use of record linkage in perinatal health research between 2001 and 2011. There was a very strong increase in publications which linked perinatal health data over time and there were also large differences in the number of studies each country contributed, the number of routine data sources used and the types of linkage which were done.

The use of record linkage increased steadily between 2001 and 2011 and $41 \%$ of the articles were published between 2009 and 2011. Three quarters of the studies were from a selected few countries namely the Nordic countries (in particular Denmark, Finland, Norway and Sweden), the US and the UK which contributed $43 \%, 19 \%$ and $12 \%$ of the publications, respectively. Australia and Canada contributed another $12 \%$ of the studies but other countries contributed many fewer; twenty two European countries published between 1 and 11 studies accounting all together for about $5 \%$ of our study sample. We compared the distribution of studies by groups of countries (Nordic, US, UK and other) between two time periods (2001-2006 and 2007-2011) and it was similar $(P=.224)$. The number of routine data sources used varied between 1 (i.e. when mother and newborn records were paired within the same data source) and 7 (mainly in the Nordic countries), but most studies used 2-3 data sources. The majority of 
Table 1 Description of perinatal health record linkage studies included in review, $N=516$

\begin{tabular}{|c|c|c|}
\hline Characteristics of studies & $\mathbf{N}$ & $\%$ \\
\hline \multicolumn{3}{|l|}{ Year of publication } \\
\hline 2001-2002 & 48 & 9.3 \\
\hline 2003-2004 & 58 & 11.2 \\
\hline 2005-2006 & 90 & 17.4 \\
\hline $2007-2008$ & 112 & 21.5 \\
\hline 2009-2011 & 208 & 40.5 \\
\hline \multicolumn{3}{|l|}{ Country } \\
\hline Nordic countries ${ }^{a}$ & 223 & 43.2 \\
\hline US & 99 & 19.2 \\
\hline UK & 63 & 12.2 \\
\hline Australia & 43 & 8.3 \\
\hline Canada & 18 & 3.5 \\
\hline Taiwan & 14 & 2.7 \\
\hline Brazil & 14 & 2.7 \\
\hline Netherlands & 12 & 2.3 \\
\hline Other countries with 1-11 studies ${ }^{\mathrm{b}}$ & 30 & 5.8 \\
\hline \multicolumn{3}{|l|}{ No. of data sources } \\
\hline $1^{\mathrm{c}}$ & 9 & 1.7 \\
\hline 2 & 293 & 56.8 \\
\hline 3 & 134 & 26.0 \\
\hline 4 or more & 80 & 15.5 \\
\hline \multicolumn{3}{|l|}{ Linkage types } \\
\hline Vital statistics: birth and death certificates & 101 & 19.6 \\
\hline Vital statistics and hospital discharge data ${ }^{d}$ & 90 & 17.4 \\
\hline Medical birth register (MBR) and hospital discharge data & 89 & 17.2 \\
\hline Vital statistics and MBR & 45 & 8.7 \\
\hline Other ${ }^{\mathrm{e}}$ & 191 & 37.0 \\
\hline Longitudinal study & 257 & 50.0 \\
\hline
\end{tabular}

a: Nordic countries include Denmark, Finland, Norway and Sweden. b: Countries include 21 EU member states, Switzerland, Singapore, China, Cuba, Ghana, Malawi, Mexico and New Zealand.

c: Linkage of mother and baby records within the same registry, or linked birth and death files from the same data source.

$\mathrm{d}$ : Hospital discharge data includes inpatient data and other medical records.

e: 'Other' linkage types exclusive to studies for which vital statistics, medical birth registry and hospital discharge data were not included in the record linkage (cf. Table 2). studies merged vital statistics data and hospital discharge data, but other linkage types were also identified.

Table 2 shows the wide variety of linkage types performed in perinatal health research between 2001 and 2011; we display the distribution of perinatal health record linkage studies for which at least two distinct types of routine data sources were used. We identified 16 types of data sources in the literature and tabulated all two-by-two linkages between these data sources as well as the total number of studies in which each type of data source was used. For example, in a Swedish study that linked three population-based data sources (the Medical birth register (MBR), hospital discharge data and the Prescription drug register), ${ }^{12}$ we counted the following two-by-two linkages: (i) MBR with Hospital discharge data, (ii) MBR with Prescription drugs register and (iii) Prescription drugs register with hospital discharge data. Linkages were distributed unevenly across routine data sources. The 254 linkages involving vital statistics data were the most common. Next, 219 linkages with medical birth registers and 203 with hospital discharge data provided more detailed data on pregnancy, delivery and the postpartum; and finally, studies linking socio-economic data from other sources, e.g. census data, were the least prevalent.

In table 3, we present the themes explored in the literature using linkage based on studies' main outcome variables and their timing of occurrence. About $62 \%$ of studies focused on infant health outcomes, $20 \%$ of studies focused on maternal health outcomes and $14 \%$ of studies focused on use of linkage to validate data quality and completeness, and on the accuracy of methods for linking perinatal data. Nearly $40 \%$ of maternal and infant health studies were longitudinal and examined health issues and associations outside of the perinatal period.

Among the 342 infant health studies, $60 \%$ focused on perinatal issues such as fetal, neonatal or infant mortality, congenital anomalies, preterm births, births small-for-gestational age and low birth weight. Linkage techniques were also used to study longer term outcomes such as child health, need for health services, highest level of education, motor and cognitive development of babies born atrisk of adverse outcomes such as very preterm births, diabetes, asthma and adult mental health issues. For example in an English

Table 2 Distribution of perinatal health record linkage studies for which at least two distinct types of routine data sources were used; $N=2172$ two by two linkages in $N=516$ studies $^{4}$

Data Source no. 1

Data Source $n^{\circ} 2$

VS MBR HD POP Cohort Cancer CA PROF DRUGS ID PSY Insurance ART Census EDU Screening

Vital Statistics (VS)

Medical birth register (MBR)

Hospital discharge data (HD) ${ }^{\mathrm{b}}$

Other population register (POP)

Cohort study

Cancer register

Congenital anomalies register (CA)

Health professional register (PROF) ${ }^{c}$

Prescription drugs register (DRUGS)

Illness/Disability register (ID)

Psychiatric register (PSY)

Insurance

ART register (ART)

Census

Register on level of education (EDU)

Screening register

-

N 2×2 linkages ${ }^{d}$

$\mathrm{N}$ studies $^{\mathrm{d}}$

\begin{tabular}{|c|c|c|c|c|c|c|c|c|c|c|c|c|c|c|c|}
\hline 45 & - & & & & & & & & & & & & & & \\
\hline 90 & 89 & - & & & & & & & & & & & & & \\
\hline 45 & 52 & 50 & - & & & & & & & & & & & & \\
\hline 18 & 31 & 27 & 14 & - & & & & & & & & & & & \\
\hline 42 & 11 & 21 & 10 & 11 & - & & & & & & & & & & \\
\hline 32 & 22 & 19 & 6 & 6 & 4 & - & & & & & & & & & \\
\hline 13 & 26 & 18 & 8 & 2 & 3 & 9 & - & & & & & & & & \\
\hline 5 & 22 & 15 & 6 & 5 & 1 & 5 & 3 & - & & & & & & & \\
\hline 5 & 25 & 7 & 4 & 1 & 2 & 3 & 5 & 2 & - & & & & & & \\
\hline 9 & 7 & 8 & 11 & 7 & 3 & 3 & 3 & 2 & 1 & - & & & & & \\
\hline 14 & 8 & 4 & 4 & 0 & 1 & 2 & 0 & 3 & 0 & 0 & - & & & & \\
\hline 6 & 10 & 8 & 3 & 1 & 3 & 2 & 0 & 1 & 0 & 0 & 1 & - & & & \\
\hline 12 & 9 & 5 & 11 & 0 & 3 & 0 & 1 & 0 & 0 & 0 & 1 & 0 & - & & \\
\hline 9 & 18 & 4 & 6 & 1 & 0 & 2 & 0 & 0 & 1 & 0 & 1 & 1 & 1 & - & \\
\hline 10 & 6 & 7 & 0 & 2 & 1 & 5 & 3 & 0 & 0 & 1 & 0 & 0 & 0 & 0 & - \\
\hline 355 & 381 & 372 & 230 & 126 & 116 & 120 & 94 & 70 & 56 & 55 & 39 & 36 & 43 & 44 & 35 \\
\hline 254 & 219 & 203 & 96 & 80 & 70 & 56 & 37 & 31 & 29 & 22 & 22 & 19 & 19 & 18 & 18 \\
\hline
\end{tabular}

a: Birth records, death records and cause of death data.

b: Hospital discharge data includes inpatient data and other medical records.

c: Includes registries with data on pregnancy, delivery and/or the postpartum maintained by health professionals (i.e. Midwives' register of New South Wales, NVK: Paediatric Association of the Netherlands).

$\mathrm{d}$ : Studies sometimes linked more than 2 databases which explains why there are more $2 \times 2$ linkages than number of studies per data source. 
Table 3 Primary outcomes in perinatal health studies using record linkage, $N=516$

\begin{tabular}{|c|c|c|c|}
\hline Theme & Main outcomes & $\mathbf{N}$ & $\%$ \\
\hline \multirow{9}{*}{$\begin{array}{l}\text { Fetal, neonatal } \\
\text { and child health }\end{array}$} & Perinatal period & 152 & \\
\hline & $\begin{array}{l}\text { Stillbirth, neonatal or infant } \\
\text { mortality }\end{array}$ & 61 & $11 . \varepsilon$ \\
\hline & Congenital anomalies & 20 & 3.9 \\
\hline & $\begin{array}{l}\text { Preterm birth, SGA, LBW and } \\
\text { other health outcomes with or } \\
\text { without mortality }\end{array}$ & 71 & 13.8 \\
\hline & Longer term outcomes & 190 & \\
\hline & Child health and development & 84 & 16. \\
\hline & Cancer & 33 & 6. \\
\hline & $\begin{array}{l}\text { Auto-immune diseases: diabetes, } \\
\text { asthma, allergies during } \\
\text { childhood or adulthood }\end{array}$ & 23 & 4. \\
\hline & Other adult health issues & 50 & 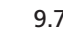 \\
\hline \multirow[t]{9}{*}{ Maternal health } & Perinatal period & 40 & \\
\hline & $\begin{array}{l}\text { Maternal mortality/severe } \\
\text { morbidity }\end{array}$ & 8 & 1. \\
\hline & Other maternal health outcomes & 25 & 4.8 \\
\hline & $\begin{array}{l}\text { Mode of delivery/obstetric } \\
\text { management }\end{array}$ & 7 & \\
\hline & Longer term outcomes & 61 & \\
\hline & $\begin{array}{l}\text { Women's health pre-conception } \\
\text { or more than } 1 \text { year post delivery }\end{array}$ & 16 & 3. \\
\hline & Cancer & 19 & \\
\hline & Auto-immune diseases & 3 & \\
\hline & Other health issues & 23 & 4. \\
\hline Methods studies ${ }^{a}$ & & 73 & 14. \\
\hline
\end{tabular}

a: Includes studies focused on validating data through record linkage use, or on usage of specific data linkage techniques. SGA: small for gestational age, LBW: low birth weight

study, a cohort of 248612 births from 1970 to 1989 in parts of the former Oxford Region in Southern England was linked to records of subsequent hospital admission for 4017 children with asthma up to 1999. ${ }^{13}$ A study in Denmark looked at the association between congenital anomalies and social position among 19874 women. ${ }^{14}$ A Norwegian study analyzed the mental health outcomes of children with congenital heart defects from age 6-36 months in a cohort of 44104 children. ${ }^{15}$ Linkage techniques have also been particularly useful for childhood cancer research ${ }^{16-25}$ and to study specific conditions such as: Legg Calve Perthes disease, ${ }^{26}$ cerebral palsy, ${ }^{27-30}$ epilepsy, ${ }^{31-34}$ neonatal encephalopathy, ${ }^{35}$ infantile hypertrophic pyloric stenosis ${ }^{36,37}$ and schizophrenia. ${ }^{38-49}$

Among the 101 maternal health studies, 57\% examined mothers' health status during the perinatal period; these publications focused on maternal morbidity (i.e. multiple sclerosis, ${ }^{50-53}$ thyroiditis, ${ }^{54,55}$ toxoplasmosis ${ }^{56}$ ), mortality, obstetric management, mode of delivery and other pregnancy complications. Record linkage was also used to study women and mothers' long term health outcomes. For example, a study in Sweden examined reproductive patterns and pregnancy outcomes of women with congenital heart disease in a population-based study of 500245 women. ${ }^{57}$ Other studies looked at pregnancy outcomes and selected conditions later in life such as hypertension and diabetes.

Among studies on methods in record linkage as applied to perinatal health, 42 focused on improvement of data quality, and other studies focused on the ascertainment of maternal and infant health outcomes, 13 and 18, respectively. Among these methods studies, 36 validated population estimates and 23 validated data items. A further 14 focused on the methods for extending routine data to serve other functions such as pharmacological surveillance and research on child abuse. From these studies, we identified procedures related to the general ascertainment of births, including underreporting of births at early gestations, completeness of population coverage and identification of multiple births. There
Table 4 Routine linkage of perinatal health data in 2014 in $26 \mathrm{EU}$ Member States ${ }^{1}$, Norway, Switzerland and Iceland by type of data linked ${ }^{2}$

\begin{tabular}{|c|c|c|c|}
\hline \multirow[b]{2}{*}{ Type of linkage $^{2}$} & \multicolumn{3}{|c|}{ Countries participating in Euro-Peristat } \\
\hline & $\mathbf{N}$ & $\%$ & Countries \\
\hline \multicolumn{4}{|l|}{$\begin{array}{l}\text { Births and hospital } \\
\text { discharge data }\end{array}$} \\
\hline $\begin{array}{l}\text { Birth certificates \& } \\
\text { hospital discharge } \\
\text { data }\end{array}$ & 2 & $7 \%$ & Sweden, UK: Scotland ${ }^{1}$ \\
\hline $\begin{array}{l}\text { Medical birth register \& } \\
\text { hospital discharge } \\
\text { data }\end{array}$ & 6 & $21 \%$ & $\begin{array}{l}\text { Estonia, Finland, Luxembourg, } \\
\text { Sweden, UK: Scotland', Iceland }\end{array}$ \\
\hline \multicolumn{4}{|l|}{ Births and deaths data } \\
\hline $\begin{array}{l}\text { Medical birth register \& } \\
\text { neonatal/infant death } \\
\text { certificates }\end{array}$ & 10 & $34 \%$ & $\begin{array}{l}\text { Cyprus, Finland, Latvia, } \\
\text { Luxembourg, Malta, Norway, } \\
\text { Sweden, UK: Scotland', } \\
\text { Iceland, Czech Republic }\end{array}$ \\
\hline $\begin{array}{l}\text { Birth certificates \& } \\
\text { neonatal/infant death } \\
\text { certificates }\end{array}$ & 10 & $34 \%$ & $\begin{array}{l}\text { Austria, Belgium, Estonia, France, } \\
\text { Germany, Poland, Sweden, } \\
\text { Switzerland, UK: England and } \\
\text { Wales' }^{1} \text {, UK: Scotland }\end{array}$ \\
\hline $\begin{array}{l}\text { Medical birth register \& } \\
\text { birth certificates }\end{array}$ & 8 & $28 \%$ & $\begin{array}{l}\text { Estonia, Finland, Slovenia, Malta, } \\
\text { Norway, Sweden, UK: } \\
\text { Scotland'1', Iceland }\end{array}$ \\
\hline Other linkages ${ }^{3}$ & 10 & $34 \%$ & 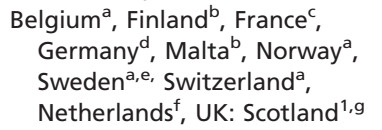 \\
\hline No routine linkage & 11 & $38 \%$ & $\begin{array}{l}\text { Denmark, Greece, Hungary, } \\
\text { Ireland, Italy, Lithuania, } \\
\text { Portugal, Romania, Slovakia, } \\
\text { Spain, UK: Northern Ireland }{ }^{1} \text {, } \\
\text { UK (national) }{ }^{1}\end{array}$ \\
\hline
\end{tabular}

1UK's four constituent countries: England, Wales, Northern Ireland and Scotland compile data separately.

${ }^{2}$ Some countries perform several types of linkages.

${ }^{3}$ Routine linkages with: a. population registers, b. congenital anomaly registers, c. vital statistics and cause-of-death data, d. regional data sources only, e. registers on level of education, f. health professional registries, g. any other national level health database on children or mothers.

were ten which related to procedures to identify maternal deaths, 7 relating to the ascertainment of fetal and infant deaths and 7 network or register audits. Some studies focused on validation of data items: 18 on the presence and characteristics of birth defects, one on assisted reproductive techniques (ART), three on obstetric history and one on social characteristics. A further 26 studies focused on metrics to validate deterministic and probabilistic linkages.

Table 4 provides an overview of routine perinatal health linkages performed in countries reporting data to Euro-Peristat. Among the 29 European countries participating in the Euro-Peristat project, 18 report using at least one type of linkage for routine statistics and 11 do not. Supplementary Annex SI provides more information on linked sources used in the 2010 report. Some countries such as Denmark can link their data systems for research projects but these linkages are not routine. Countries which currently merge national level datasets for perinatal health surveillance essentially link birth and death data but the data sources used for this type of linkage vary. Cyprus, Finland, Latvia, Luxembourg, Malta, Norway, Sweden, UK Scotland, Iceland and the Czech Republic link data from their medical birth registers with death certificates. Austria, Belgium, Estonia, France, Germany, Poland, Switzerland and UK: England and Wales routinely link their birth and death data from vital statistics data sources alone. Similarly, data on births and from hospital discharge systems can be linked using 
vital statistics as in Scotland and Sweden, or data from a medical birth register as in Luxembourg. Seven countries carry out national linkages with hospital discharge data although in Germany this is done at the regional level only, in Lower Saxony. Other reported linkages involve congenital anomaly registers, cause-of-death data, registers on level of education, or are done at the regional-level only. These other linkages are exclusively performed in countries where birth and death data are routinely linked at the national level.

\section{Discussion}

By harmonizing data systems, and ensuring completeness of coverage, record linkage increases the information available about each birth and can enhance the quality of perinatal health data. However, our review shows that this technique is largely underused in Europe: 11 out of 29 countries do not routinely link data on births and only 18 countries perform basic linkages such as linking birth and death certificates. Also, linkage studies were concentrated in a small set of countries; almost half of the studies published from 2001 to 2011 originated from the Nordic countries $(N=223)$. In the Nordic countries, the types of linkages performed for perinatal health surveillance were also more diverse than anywhere else in Europe.

Historical differences in health information capacity between countries may explain some of the variation in record linkage use in Europe. In England and Wales for instance, initiatives to link birth and death certificates began in 1950 in order to maximize the value of existing routine data and develop capacity for analyses of perinatal and infant mortality ${ }^{58}$ - this linkage has been routine since 1975. The Oxford Record Linkage Study (ORLS), which started in the 1960s was seminal as both a research tool and a means to improve the quality of health care services. ${ }^{13,58,59}$ The Nordic countries have also had a long standing tradition of maintaining birth registers, as early as the 1950 s in some countries, ${ }^{60,61}$ and this has allowed for broader application of linkage techniques in perinatal health research. Longer follow-up time broadens the scope of potential research questions and enables studies across generations.

The reasons for linkage are related to the organization of the health and data collection systems and these vary across countries. For example, in the Netherlands, midwives, general practitioners, obstetricians and neonatologist have separate databases which are linked to bring together perinatal care data for women who have been client of more than one profession, ${ }^{62}$ but other countries do not need to do this. Another example relates to cause of death recording: in the UK causes of death are recorded on stillbirth and death certificates, while in France linkage is necessary to access this information because civil registration of deaths is distinct from the medical certification of the causes. ${ }^{7}$

Capacity for linkage also depends on the availability of matching variables. Whereas many national registers in Europe anonymize their records, others countries and in particular the Nordic countries make universal identification numbers available in all their routine databases. ${ }^{8}$ Universal identifiers facilitate linkage between statistical, administrative and health authorities, although in the absence of identifying variables probabilistic techniques can be used. ${ }^{63}$ In the Netherlands, validation of the probabilistic approach applied to the Dutch Perinatal registers yielded less than $1 \%$ error. ${ }^{62}$

There are multiple obstacles associated with linkage including cultural, organizational, structural, legal and technical issues. Specific obstacles identified in research on linkage include high costs, lack of software compatibility, need for additional statistical training, poor access to electronic records, missing data or varying interpretations of data privacy frameworks across organizations. ${ }^{64-66}$ Data systems are also often managed by different institutions and communication and identification of common goals may hamper efforts to merge data sources. Moreover, concerns over privacy and the biases introduced when linkages are incomplete may influence countries' willingness to institute routine linkage. Further research is needed to explore these obstacles, particularly how they have been overcome in countries that have instituted routine linkage, and their relative weight in countries where linkage is underdeveloped.

Our results underscore the multiple ways that record linkage can improve capacity for high quality perinatal health surveillance. First of all, data from the methods studies in the literature review showed that linkage can be used for validation and to ascertain new perinatal data items and outcomes. ${ }^{62,65,67,68}$ In France for instance, linkage of the deaths of women of childbearing age to birth records and hospital discharge data makes it possible to account for all maternal deaths and reduce underreporting. ${ }^{7}$ Further, by linking birth certificate data on gestational age and birth weight with death certificates it is possible to calculate subgroup mortality rates which are essential for monitoring infant health status and understanding patterns of mortality over time. ${ }^{3,6,65,69,70}$ Because vital statistics data are available everywhere in Europe, ${ }^{1}$ basic linkage of birth and death certificates should be possible in all countries. All European countries also have hospital discharge data, ${ }^{71}$ yet routine linkage of these data with birth certificates and other population datasets was only carried out in only a fourth of countries.

Data on hospitalizations contain valuable information about clinical procedures and diagnoses because their primary use is for management and financing. ${ }^{6}$ Basic socioeconomic characteristics are rarely included in hospital data, but these can be retrieved from other data sources, such as census data or registers on education, occupation and income. Birth certificate data in most countries provide information on characteristics such as place of birth, place of residence, marital status or occupation. Hence, linkage between hospital discharge data and population-based registers can be used to assess the burden of health disparities across socio-economic groups. ${ }^{72-74}$ The additional variables acquired through linkage allow for more refined and expanded analyses of trends and patterns in key perinatal indicators. ${ }^{67,69,75-82}$

Record linkage also enables the surveillance of specific clinical subgroups such as infants born with congenital anomalies or from ART. Whereas only two countries, Finland and Malta, conduct routine linkages with their congenital anomaly registers, these types of linkages were frequent in the literature. In about $15 \%$ of studies, researchers focused on the impact of ART as well as on the effects of teratogens and prescription drugs on congenital anomalies. For example, two US studies looked at exposure to anesthetic gases and congenital anomalies in offspring of female registered nurses ${ }^{83}$ and the association between maternal exposure to ambient air pollution and congenital heart disease. ${ }^{84}$

More generally, our review shows that linkage of routine data systems is a valuable tool for research which can provide insight into maternal and infant health indicators but also into the etiology, prognosis and consequences of conditions such as Legg Calves Perthes disease, cerebral palsy, or multiple sclerosis. Linkage of routine systems also facilitates life-course research on the long term outcomes of mothers and their newborns. Half of the studies in our review were longitudinal. A cohort, e.g. of all women of reproductive age, can be identified and monitored by linking data relating to these women from multiple data sources thereby increasing the power of statistical analyses without having to incur the costs of a long follow-up time.

This systematic review builds on a large number of studies linking routine databases on perinatal health. We also identified countries in which linkage is currently undertaken for routine perinatal health monitoring to get information about the linkages put in place and to permit other countries to benefit from their experience. In countries where specific data sets are linked regularly, as in the Nordic countries, authors did not always explicitly mention 'linkage' in the abstracts. This could have led to an under-estimation of the 
number of perinatal health studies published during our review period. We only included studies in referenced databases and thus did not include studies published on statistical institution's websites only or other types of grey literature such as agency health and policy reports. Also, countries differed in the terminologies they used for their data sources, especially when translating them into English and this can make it difficult to distinguish between e.g. a morbidity database, hospital records and a birth register.

Data linkage increases the availability of data for surveillance and assessment of differences across countries and over time. Linkage techniques can also contribute to the generation of knowledge about the causes and consequences of ill health. More specifically, linkage of data from birth and death certificates provides more and higher quality information about mortality and should be prioritized in countries where these sources are not yet linked. Linking hospital discharge data and civil registration data should also be a priority as it increases the amount of information available about each birth and can be used to double check the completeness of registration of births and deaths in hospital databases. Finally, linkage makes it possible to augment commonly available birth data with information on specific outcomes or exposures in relation to health and well-being across the life course. These linkages will depend on other existing databases (i.e. congenital anomalies registers, pharmaceutical databases) and the use of linkage for surveillance and research in other health areas and sectors such as education, employment or housing.

In conclusion, some countries integrate data linkage into their routine perinatal health surveillance systems and make these data available for research, but this is not a universal practice throughout Europe. Current discussion at the EU-level and across Member States includes moving towards the establishment of a European health information system, and strengthening health reporting mechanisms. ${ }^{85,86}$ Linking data on perinatal health is a feasible and readily available option for improving the quality and completeness of health indicators thereby adding value to existing national and international investment in health information. Further research is needed on the obstacles to linkage in countries which do not practice it routinely. Promoting these recommendations about the linkages which are most useful for perinatal health reporting and broader adoption of linkage could yield substantial gains for research and surveillance of perinatal health nationally and internationally.

\section{Supplementary data}

Supplementary data are available at EURPUB online.

\section{Acknowledgements}

The member of the The Euro-Peristat Scientific Committee include: Gerald Haidinger (Austria), Sophie Alexander (Belgium), Pavlos Pavlou (Cyprus), Petr Velebil (Czech Republic), Laust Mortensen (Denmark), Luule Sakkeus (Estonia), Mika Gissler (Finland), Béatrice Blondel (France), Nicholas Lack (Germany), Aris Antsaklis (Greece), István Berbik (Hungary), Helga Sól Ólafsdóttir (Iceland), Sheelagh Bonham (Ireland), Marina Cuttini (Italy), Janis Misins (Latvia), Jone Jaselioniene (Lithuania), Yolande Wagener (Luxembourg), Miriam Gatt (Malta), Jan Nijhuis (Netherlands), Kari Klungsøyr (Norway), Katarzyna Szamotulska (Poland), Henrique Barros (Portugal), Mihai Horga (Romania), Jan Cap (Slovakia), Živa Novak Antolič (Slovenia), Francisco Bolúmar (Spain), Karin Gottvall (Sweden), Sylvie Berrut (Switzerland), Alison Macfarlane (United Kingdom). Project coordination: Jennifer Zeitlin, Marie Delnord, Ashna Hindori-Mohangoo.

The authors acknowledge the following contributors to the European Perinatal Health Report: Health and Care of Pregnant Women and Babies in Europe in 2010:
Austria, Gerald Haidinger, The Medical University of Vienna, Department of Epidemiology, Centre of Public Health; Jeannette Klimont, Statistics Austria; Belgium, Sophie Alexander, Wei-Hong Zhang, Michèle Dramaix-Wilmet, Mélissa Van Humbeeck, Université Libre de Bruxelles, School of Public Health, Epidemiology, Biostatistics and Clinical Research Centre; Charlotte Leroy, Anne-Frédérique Minsart, Virginie van Leeuw, Centre d'Epidémiologie Périnatale (Cepip); Evelyne Martens, SPE (Study Center for Perinatal Epidemiology); Myriam De Spiegelaere, Brussels Health and Social Observatory, Freddy Verkruyssen, Michel Willems, FPS Economy, SMEs, Self-employed and Energy; Willem Aelvoet, The Federal Public Service (FPS) Health, Food Chain Safety and Environment; Jean Tafforeau, Francoise Renard, Denise Walckiers, Focal Point for the data collection on national health statistics for Eurostat, OECD and WHO; Deborah Cuignet, Philippe Demoulin, French Community of Belgium; Heidi Cloots, Erik Hendrickx, Anne Kongs, Flemish Agency for Care and Health; Cyprus, Pavlos Pavlou, Despina Stylianou, Theopisti Kyprianou, Ministry of Health, Health Monitoring Unit; Nicos Skordes, Pediatric Department, Makarios III Hospital; Czech Republic, Petr Velebil, Institute for the Care of Mother and Child; Denmark, Jens Langhoff Roos, Obstetrics Clinic, Rigshospitalet, Copenhagen University; Anne-Marie Nybo Anderson, Laust Hvas Mortensen, University of Copenhagen; Estonia, Luule Sakkeus, Estonian Institute for Population Studies, Tallinn University; Finland, Mika Gissler, Anna Heino, Annukka Ritvanen, THL National Institute for Health and Welfare; France, Béatrice Blondel, Marie-Hélène Bouvier Colle, Marie Delnord, Jennifer Zeitlin, National Institute of Health and Medical Research (INSERM) U1153; Anne Ego, RHEOP Register for Disabled Children and Perinatal Observatory; Grégoire Rey, National Center of Statistics for Medical Causes of Death (CépiDc), National Institute of Health and Medical Research (INSERM); Germany, Nicholas Lack, Bavarian Institute for Quality Assurance; Guenther Heller, AQUA-Institut; Anton Scharl, Department of Obstetrics and Gynaecology; Klinikum Amberg; Greece, Aris Antsaklis, Peter Drakakis, Athens University Medical School, Athens; Hungary, István Berbik, Department of Obstetrics and Gynaecology, Vaszary Kolos Teaching Hospital; Iceland, Helga Sól Ólafsdóttir, Ragnheiður I. Bjarnadottir, Hildur Harðardóttir, Brynja Ragnarsdóttir, Vigdís Stefánsdóttir Landspitali University Hospital; Sigríður Haraldsdóttir, Landlaeknis Directorate of Health; Ireland, Sheelagh Bonham, Aisling Mulligan, The Healthcare Pricing Office (HPO); Italy, Marina Cuttini, Pediatric Hospital of Baby Jesus, Unit of Epidemiology; Cristina Tamburini, Rosaria Boldrini, General Directorate for the Health Information and Statistical System, Italian Ministry of Health; Sabrina Prati, Marzia Loghi, Cinzia Castagnaro, Stefano Marchetti, Alessandra Burgio, Central Directorate for Socio-demographic and Environmental Statistics, Italian National Institute for StatisticsISTAT; Monica Da Frè, Epidemiology Observatory, Regional Agency for Health of Tuscany Latvia, Janis Misins, Irisa Zile, The Centre for Disease Prevention and Control of Latvia; Lithuania, Jelena Isakova, Rita Gaidelyte, Jone Jaselione, Institute of Hygiene, Health information centre; Luxembourg, Yolande Wagener, Guy Weber Ministry of Health, Department of Health, Division of Preventive and Social Medicine; Audrey Billy, Aline TouvreyLecomte, Public Health Research Center; Malta, Miriam Gatt, Dept of Health Information and Research, National, Obstetric Information Systems (NOIS) Register; Netherlands, Jan Nijhuis, Maastricht University Medical Center, Department of Obstetrics \& Gynecology, Maastricht; Karin van der Pal -de Bruin and Ashna Hindori- Mohangoo, TNO Healthy Living, Department Child Health, Leiden; Peter Achterberg, National Institute for Public Health and the Environment; Chantal Hukkelhoven and Ger de Winter, The Netherlands Perinatal Registry; Anita Ravelli, Academic Medical Research Center; Greta Rijninks-van Driel, The Royal Dutch College of Midwives; Pieter Tamminga, Paediatric Association of the Netherlands; Martin Groesz, Perinatal Audit 
Netherlands; Patsy Elferink-Stinkens, Statistics Netherlands; Norway, Kari Klungsoyr, Medical Birth Registry of Norway, Norwegian Institute of Public Health and Department of Global Public Health and Primary Care, University of Bergen; Arild Osen, Marta Ebbing, Medical Birth Registry of Norway, The Norwegian Institute of Public Health; Poland, Katarzyna Szamotulska, National Research Institute of Mother and Child, Department of Epidemiology and Biostatistics with collaboration from The Central Statistical Office, the National Health Fund and Ministry of Health; Portugal, Henrique Barros, Sofia Correia, University of Porto Medical School, Department of Clinical Epidemiology, Predictive Medicine and Public Health; Institute of Public Health; Romania, Mihai Horga, Senior Advisor at the East European Institute for Reproductive Health, East European Institute for Reproductive Health; Alexandra Cucu, National Institute of Public Health; Slovakia, Jan Cap, National Health Information Center; Slovenia, Živa Novak-Antolič, University Medical Centre, Perinatology Unit, Ljubljana University; Ivan Verdenik, University Medical Centre, Department of Obstetrics\& Gynecology, Research Unit; Spain, Francisco Bolumar, Alcala University Medical School; Mireia Jané, Maria José Vidal, Public Health Surveillance Direction, Catalan Public Health Agency; Carmen Barona, Rosa Mas, Public Health, Generalitat Valenciana; Adela Recio Alcaide, National Institute for Statistics (INE); Sweden, Karin Gottvall, Ellen Lundqvist, The National Board of Health and Welfare, Department of Statistics, Monitoring and Evaluation, Statistics on Public Health and Social Care Unit; Switzerland, Sylvie Berrut, Swiss Federal Statistical Office, Section Health; Claudia König, Monika Schmid, Institut für Hebammen, ZHAW Zürcher, Hochschule für Angewandet Wissenschaften; United Kingdom, Alison Macfarlane, Nirupa Dattani, City University London; Jim Chalmers (now retired), Kirsten Monteath, Information Services Division, NHS National Services Scotland; Marie Climson, National Records of Scotland; Leslie Marr, Healthcare Improvement Scotland; Rod Gibson, Birthchoice UK; Gwyneth Thomas, Rhian Osborne, Health Statistics and Analysis Unit, Welsh Government; Russell Brown, NHS Wales Informatics Service; David Sweet, Joanne Evans, Office for National Statistics; Sinead Magill, Adele Graham, Heather Reid, Public Health Agency; Terry Falconer, Karen McConnell, Northern Ireland Maternal and Child Health, Public Health Agency (now retired); Neil McComb, Human Fertilisation and Embryology Authority.

\section{Funding}

This study was funded by grants from the European Commission for the Euro-Peristat project: 20101301 and for the Bridge Health project: 664691. The funding agency was not involved in the study. This study used aggregated national indicators, ethical approval was not required.

Conflicts of interest: None declared.

\section{Key points}

- Record linkage has been successfully used for research on maternal, fetal and infant health risk factors and outcomes, although this research is concentrated in only a few countries.

- That linkages are not systematic practice for perinatal health surveillance could explain gaps in data availability in the European Perinatal Health Report 2010 and limitations in countries' capacity to collect data for key subgroup populations.
- Linking data on perinatal health is a feasible and readily available option for improving the quality and completeness of health indicators thereby adding value to existing national and international investments in health information systems.

- Having common recommendations in the EU about which linkages are most useful for perinatal health reporting and broader adoption of linkage could yield substantial gains for research and surveillance of perinatal health nationally and internationally.

\section{References}

1 Euro-Peristat project with SCPE and Eurocat. European Perinatal Health Report: The health and care of pregnant women and babies in Europe in 2010. 2013. Available from www.europeristat.com

2 Zeitlin J, Mohangoo AD, Delnord M, et al. The second European Perinatal Health Report: documenting changes over 6 years in the health of mothers and babies in Europe. J Epidemiol Community Health 2013;67:983-5.

3 Mohangoo AD, Blondel B, Gissler M, et al. International comparisons of fetal and neonatal mortality rates in high-income countries: should exclusion thresholds be based on birth weight or gestational age? PloS One 2013;8:e64869

4 Delnord M, Blondel B, Drewniak N, et al. Varying gestational age patterns in cesarean delivery: an international comparison. BMC Pregnancy Childb 2014;14:321

5 Macfarlane A, Blondel B, Mohangoo A, et al. Wide differences in mode of delivery within Europe: risk-stratified analyses of aggregated routine data from the EuroPeristat study. BJOG: an international journal of obstetrics and gynaecology. Br J Obstet Gynaecol 2015. DOI: 10.1111/1471-0528.13284.

6 Gissler M, Mohangoo AD, Blondel B, et al. Perinatal health monitoring in Europe: results from the EURO-PERISTAT project. Inf. Health Soc Care 2010;35:64-79.

7 Bouvier-Colle $\mathrm{MH}$, Mohangoo AD, Gissler M, et al. What about the mothers? An analysis of maternal mortality and morbidity in perinatal health surveillance systems in Europe. BJOG Int J Obstetrics Gynaecol 2012;119:880-9; discussion 90.

8 Henningsen AK, Romundstad LB, Gissler M, et al. Infant and maternal health monitoring using a combined Nordic database on ART and safety. Acta Obstetricia Gynecol Scand 2011;90:683-91.

9 Barfield WD, Clements KM, Lee KG, et al. Using linked data to assess patterns of early intervention (EI) referral among very low birth weight infants. Mater Child Health J 2008;12:24-33.

10 Croft ML, Morgan V, Read AW, Jablensky AS. Recorded pregnancy histories of the mothers of singletons and the mothers of twins: a longitudinal comparison. Twin Res Hum Genet Off J Int Soc Twin Stud 2010;13:595-603.

11 Gissler M, Klemetti R, Sevon T, Hemminki E. Monitoring of IVF birth outcomes in Finland: a data quality study. BMC Med Inform Decis Mak 2004;4:3

12 Dehlink E, Yen E, Leichtner AM, et al. First evidence of a possible association between gastric acid suppression during pregnancy and childhood asthma: a population-based register study. Clin Exp Aller 2009;39:246-53.

13 Davidson R, Roberts SE, Wotton CJ, Goldacre MJ. Influence of maternal and perinatal factors on subsequent hospitalisation for asthma in children: evidence from the Oxford record linkage study. BMC Pulm Med 2010;10:14

14 Olesen C, Thrane N, Ronholt AM, et al. Association between social position and congenital anomalies: a population-based study among 19,874 Danish women. Scand J Public Health 2009;37:246-51.

15 Stene-Larsen K, Brandlistuen RE, Holmstrom H, et al. Longitudinal analysis of emotional problems in children with congenital heart defects: a follow-up from age 6 to 36 months. J Dev Behav Pediatr 2011;32:461-4.

16 Zhu JL, Basso O, Hasle H, et al. Do parents of children with congenital malformations have a higher cancer risk? A nationwide study in Denmark. Br J Cancer 2002;87:524-8.

17 Stavrou EP, Baker DF, Bishop JF. Maternal smoking during pregnancy and childhood cancer in New South Wales: a record linkage investigation. Cancer Causes Contr 2009;20:1551-8.

18 Spector LG, Puumala SE, Carozza SE, et al. Cancer risk among children with very low birth weights. Pediatrics 2009;124:96-104. 
19 Paltiel O, Laniado DE, Yanetz R, et al. The risk of cancer following hospitalization for infection in infancy: a population-based cohort study. Cancer Epidemiol Biomarkers Prev 2006;15:1964-8.

20 Mueller BA, Chow EJ, Kamineni A, et al. Pregnancy outcomes in female childhood and adolescent cancer survivors: a linked cancer-birth registry analysis. Arch Pediatr Adolesc Med 2009;163:879-86.

21 Kallen B, Finnstrom O, Nygren KG, Olausson PO. In vitro fertilization in Sweden: child morbidity including cancer risk. Fertil Steril 2005;84:605-10.

22 Chow EJ, Puumala SE, Mueller BA, et al. Childhood cancer in relation to parental race and ethnicity: a 5-state pooled analysis. Cancer 2010;116:3045-53.

23 Chow EJ, Kamineni A, Daling JR, et al. Reproductive outcomes in male childhood cancer survivors: a linked cancer-birth registry analysis. Arch Pediatr Adolesc Med 2009;163:887-94.

24 Brewster DH, Tucker JS, Fleming M, et al. Risk of skin cancer after neonatal phototherapy: retrospective cohort study. Arch Dis Child 2010;95:826-31.

25 Agha MM, Williams JI, Marrett L, et al. Congenital abnormalities and childhood cancer. Cancer 2005;103:1939-48.

26 Bahmanyar S, Montgomery SM, Weiss RJ, Ekbom A. Maternal smoking during pregnancy, other prenatal and perinatal factors, and the risk of Legg-Calve-Perthes disease. Pediatrics 2008;122:e459-64.

27 Smith L, Kelly KD, Prkachin G, Voaklander DC. The prevalence of cerebral palsy in British Columbia, 1991-1995. Can J Neurol Sci 2008;35:342-7.

28 O'Callaghan ME, MacLennan AH, Gibson CS, et al. The Australian cerebral palsy research study-protocol for a national collaborative study investigating genomic and clinical associations with cerebral palsy. J Paediatr Child Health 2010;47:99-110.

29 Moster D, Wilcox AJ, Vollset SE, et al. Cerebral palsy among term and postterm births. JAMA 2010;304:976-82.

$30 \mathrm{Li} \mathrm{J}$, Vestergaard M, Obel C, et al. Prenatal stress and cerebral palsy: a nationwide cohort study in Denmark. Psychosom Med 2009;71:615-8.

31 Whitehead E, Dodds L, Joseph KS, et al. Relation of pregnancy and neonatal factors to subsequent development of childhood epilepsy: a population-based cohort study. Pediatrics 2006;117:1298-306.

32 Oyen N, Vollset SE, Eide MG, et al. Maternal epilepsy and offsprings' adult intelligence: a population-based study from Norway. Epilepsia 2007;48:1731-8.

33 Murphy DJ, Libby G, Chien P, et al. Cohort study of forceps delivery and the risk of epilepsy in adulthood. Am J Obstet Gynecol 2004;191:392-7.

34 Ehrenstein V, Pedersen L, Holsteen V, et al. Postterm delivery and risk for epilepsy in childhood. Pediatrics 2007;119:e554-61.

35 Blume HK, Loch CM, Li CI. Neonatal encephalopathy and socioeconomic status: population-based case-control study. Arch Pediatr Adolesc Med 2007;161:663-8.

36 Sommerfield T, Chalmers J, Youngson G, et al. The changing epidemiology of infantile hypertrophic pyloric stenosis in Scotland. Arch Dis Child 2008;93:1007-11

37 Cooper WO, Ray WA, Griffin MR. Prenatal prescription of macrolide antibiotics and infantile hypertrophic pyloric stenosis. Obstet Gynecol 2002;100:101-6.

38 Sorensen HJ, Nielsen PR, Pedersen CB, Mortensen PB. Association between prepartum maternal iron deficiency and offspring risk of schizophrenia: populationbased cohort study with linkage of Danish national registers. Schizophr Bull 2011;37:982-7.

39 Sorensen HJ, Mortensen EL, Reinisch JM, Mednick SA. Parental psychiatric hospitalisation and offspring schizophrenia. World J Biol Psychiatry 2009;10:571-5.

40 Sorensen HJ, Mortensen EL, Reinisch JM, Mednick SA. Do hypertension and diuretic treatment in pregnancy increase the risk of schizophrenia in offspring? Am J Psychiatry 2003;160:464-8.

41 Smits L, Pedersen C, Mortensen P, van Os J. Association between short birth intervals and schizophrenia in the offspring. Schizophr Res 2004;70:49-56.

42 Nilsson E, Hultman CM, Cnattingius S, et al. Schizophrenia and offspring's risk for adverse pregnancy outcomes and infant death. Br J Psychiatry 2008;193:311-5.

43 Moilanen K, Jokelainen J, Jones PB, et al. Deviant intrauterine growth and risk of schizophrenia: a 34-year follow-up of the Northern Finland 1966 Birth Cohort. Schizophr Res 2010;124:223-30.

44 Malaspina D, Harlap S, Fennig S, et al. Advancing paternal age and the risk of schizophrenia. Arch Gen Psychiatry 2001;58:361-7.

45 Malaspina D, Corcoran C, Kleinhaus KR, et al. Acute maternal stress in pregnancy and schizophrenia in offspring: a cohort prospective study. BMC Psychiatry 2008;8:71
46 Kimhy D, Harlap S, Fennig S, et al. Maternal household crowding during pregnancy and the offspring's risk of schizophrenia. Schizophr Res 2006;86:23-9.

47 Lichtenstein P, Yip BH, Bjork C, et al. Common genetic determinants of schizophrenia and bipolar disorder in Swedish families: a population-based study. Lancet 2009;373:234-9.

48 Khashan AS, Abel KM, McNamee R, et al. Higher risk of offspring schizophrenia following antenatal maternal exposure to severe adverse life events. Arch Gen Psychiatry 2008;65:146-52.

49 Jablensky AV, Morgan V, Zubrick SR, et al. Pregnancy, delivery, and neonatal complications in a population cohort of women with schizophrenia and major affective disorders. Am J Psychiatry 2005;162:79-91.

50 Montgomery SM, Lambe M, Olsson T, Ekbom A. Parental age, family size, and risk of multiple sclerosis. Epidemiology 2004;15:717-23.

51 Lu E, Dahlgren L, Sadovnick A, et al. Perinatal outcomes in women with multiple sclerosis exposed to disease-modifying drugs. Mult Scler 2012;18:460-7.

52 Dahl J, Myhr KM, Daltveit AK, Gilhus NE. Pregnancy, delivery and birth outcome in different stages of maternal multiple sclerosis. J Neurol 2008;255:623-7.

53 Chen YH, Lin HL, Lin HC. Does multiple sclerosis increase risk of adverse pregnancy outcomes? A population-based study. Mult Scler 2009;15:606-12.

54 Yasmeen S, Cress R, Romano PS, et al. Thyroid cancer in pregnancy. Int J Gynaecol Obstet 2005;91:15-20.

55 Galanti MR, Cnattingius S, Granath F, et al. Smoking and environmental iodine as risk factors for thyroiditis among parous women. Eur J Epidemiol 2007;22:467-72.

56 Austeng ME, Eskild A, Jacobsen M, et al. Maternal infection with toxoplasma gondii in pregnancy and the risk of hearing loss in the offspring. Int J Audiol 2010;49:65-8.

57 Josefsson A, Kernell K, Nielsen NE, et al. Reproductive patterns and pregnancy outcomes in women with congenital heart disease-a Swedish population-based study. Acta Obstetricia Gynecol Scand 2011;90:659-65.

58 Acheson ED. The Oxford record linkage study: a review of the method with some preliminary results. Proc R Soc Med 1964;57:269-74.

59 Heady JA, Stevens CF, Daly C, Morris JN. Social and biological factors in infant mortality. IV. The independent effects of social class, region, the mother's age and her parity. Lancet 1955;268:499-503.

60 Gissler M, Louhiala P, Hemminki E. Nordic Medical Birth Registers in epidemiological research. Eur J Epidemiol 1997;13:169-75.

61 Langhoff-Roos J, Krebs L, Klungsoyr K, et al. The Nordic medical birth registers a potential goldmine for clinical research. Acta Obstetricia Gynecol Scand 2014;93: $132-7$.

62 Tromp M, Meray N, Ravelli AC, et al. Medical Record Linkage of Anonymous Registries without Validated Sample Linkage of the Dutch Perinatal Registries. Stud Health Technol Inform 2005;116:125-30.

63 Meray N, Reitsma JB, Ravelli AC, Bonsel GJ. Probabilistic record linkage is a valid and transparent tool to combine databases without a patient identification number. J Clin Epidemiol 2007;60:883-91.

64 Boyd JH, Randall SM, Ferrante AM, et al. Technical challenges of providing record linkage services for research. BMC Med Inform Decis Mak 2014;14:23

65 Dattani N, Datta-Nemdharry P, Macfarlane A. Linking maternity data for England, 2005-06: methods and data quality. Health Stat Q 2011;49:53-79.

66 Grzeskowiak LE, Gilbert AL, Morrison JL. Methodological challenges in using routinely collected health data to investigate long-term effects of medication use during pregnancy. Therapeutic Adv Drug Saf 2013;4:27-37.

67 Melve KK, Lie RT, Skjaerven R, et al. Registration of Down syndrome in the Medical Birth Registry of Norway: validity and time trends. Acta Obstetricia Gynecol Scand $2008 ; 87: 824-30$

68 Tromp M, Ravelli AC, Meray N, et al. An efficient validation method of probabilistic record linkage including readmissions and twins. Methods Inf Med 2008;47:356-63.

69 Tandberg A, Bjorge T, Bordahl PE, Skjaerven R. Increasing twinning rates in Norway, 1967-2004: the influence of maternal age and assisted reproductive technology (ART). Acta Obstetricia Gynecol Scand 2007;86:833-9.

70 Quantin C, Gouyon B, Avillach P, et al. Using discharge abstracts to evaluate a regional perinatal network: assessment of the linkage procedure of anonymous data. Int J Telemed Appl 2009;2009:181842

71 Magee HF. The Hospital Data Project: comparing hospital activity within Europe Eur J Public Health 2003;13:73-9. 
72 Hockley C, Quigley MA, Hughes G, et al. Linking Millennium Cohort data to birth registration and hospital episode records. Paediatric Perinatal Epidemiol 2008;22: 99-109.

73 Guevara JP, Young JC, Mueller BA. Do protective factors reduce the risk of hospitalization in infants of teenaged mothers? Arch Pediatr Adolesc Med 2001;155: $66-72$.

74 Mittendorfer-Rutz E, Rasmussen F, Wasserman D. Restricted fetal growth and adverse maternal psychosocial and socioeconomic conditions as risk factors for suicidal behaviour of offspring: a cohort study. Lancet 2004;364:1135-40.

75 Wen SW, Joseph KS, Kramer MS, et al. Recent trends in fetal and infant outcomes following post-term pregnancies. Chronic Dis Can 2001;22:1-5.

76 Salehi S, Eloranta S, Johansson AL, et al. Reporting and incidence trends of hydatidiform mole in Sweden 1973-2004. Acta Oncol 2011;50:367-72.

77 Glynn A, Collins V, Halliday J. Utilization of genetic counseling after diagnosis of a birth defect-trends over time and variables associated with utilization. Genet Med 2009;11:287-93.

78 Bourke J, Bower C, Blair E, et al. The effect of terminations of pregnancy for fetal abnormalities on trends in mortality to one year of age in Western Australia. Paediatric Perinatal Epidemiol 2005;19:284-93.

79 Arntzen A, Mortensen L, Schnor O, et al. mortality by maternal education - a population-based study of trends in the Nordic countries, 1981-2000. Eur J Public Health 2008;18:245-51.
80 Arntzen A, Samuelsen SO, Bakketeig LS, Stoltenberg C. Socioeconomic status and risk of infant death. A population-based study of trends in Norway, 1967-1998. Int J Epidemiol 2004;33:279-88.

81 Alexander GR, Wingate MS, Bader D, Kogan MD. The increasing racial disparity in infant mortality rates: composition and contributors to recent US trends. Am J Obstet Gynecol 2008;198:51 e1-9.

82 Roberts CL, Ford JB, Algert CS, et al. Population-based trends in pregnancy hypertension and pre-eclampsia: an international comparative study. BMJ Open 2011;1:e00010

83 Teschke K, Abanto Z, Arbour L, et al. Exposure to anesthetic gases and congenital anomalies in offspring of female registered nurses. Am J Ind Med 2011;54: $118-27$.

84 Dadvand P, Rankin J, Rushton S, Pless-Mulloli T. Association between maternal exposure to ambient air pollution and congenital heart disease: A register-based spatiotemporal analysis. Am J Epidemiol 2011;173:171-82.

85 European Commission. DG Health and Food Safety. Improving Health Reporting Mechanisms. Available from http://ec.europa.eu/health/data_collection/tools/ mechanisms/index_en.htm

86 Expert Group on Health Information. Non-paper on 'Health Information System European Research Infrastructure Consortium' - HIS ERIC. 2013. Available from http://ec.europa.eu/health/strategy/docs/non_paper_his_eric_en.pdf

The European Journal of Public Health, Vol. 26, No. 3, 430-432

(c) The Author 2016. Published by Oxford University Press on behalf of the European Public Health Association. All rights reserved. doi:10.1093/eurpub/ckw035 Advance Access published on 24 March 2016

\title{
Short Report
}

\section{Effects of small incentives on survey response fractions: randomised comparisons in national alcohol surveys conducted in New Zealand}

\author{
Kypros Kypri ${ }^{1,2}$, Brett Maclennan ${ }^{1}$, Jennie L. Connor ${ }^{1}$ \\ 1 Department of Preventive and Social Medicine, University of Otago, Dunedin, New Zealand \\ 2 School of Medicine and Public Health, University of Newcastle, Australia
}

Correspondence: Kypros Kypri, Room 4104, HMRI Building, Kookaburra Circuit, New Lambton Heights NSW 2305 Australia, Tel: +612 4042 0536, Fax: +612 4042 0044; e-mail: kypros.kypri@newcastle.edu.au

We experimentally evaluate inexpensive interventions to increase response fractions in two alcohol surveys. Residents on the New Zealand General and Māori electoral rolls were randomized to receive a survey pack with or without an offer of entry to a $\$ 500$ prize draw. Subsequent randomization of sample members who did not initially respond allowed estimation of effects of offering a $\$ 5$ donation to charity as an incentive to respond. Offering prize draw entry did not significantly increase responses in either population. Contrary to expectation, promising a $\$ 5$ donation to non-respondents reduced subsequent responding in the group previously offered the prize draw incentive.

\section{Background}

Ealling response fractions present a challenge for health research, Freducing effective sample sizes and, more importantly, increasing the potential for bias in estimates due to non-response being associated with variables of interest. The problem is illustrated by a recent coronary disease study, in which 1886 patients who completed a survey about their quality of life were compared with 506 who did not complete the survey (response fraction $79 \%$ ). Consistent with the survey methods literature, non-respondents were younger, had greater body mass, and a larger proportion were smokers. They were also two to four times more likely to die in the following 3 years, leading the authors to conclude that 'Data gathered by means of questionnaires cannot be generalized to the whole patient population due to a profound non-response bias' (p. 168). ${ }^{1}$

Correcting for non-response bias is problematic because it relies on naïve assumptions about distributions of the characteristics of interest within the non-respondents. ${ }^{2}$ The best approach is to minimize non-response through study design. A systematic review of methods to increase response rates in postal surveys showed increasing response fractions from a range of strategies including the use of monetary and non-monetary incentives, unconditional incentives, reminder contacts and provision of replacement questionnaires on request. ${ }^{3}$ 